\title{
Results of a national web-based survey on the SARS-CoV-2 infectious state of otorhinolaryngologists in Germany
}

\author{
Michael Herzog ${ }^{1}$ (1) $\cdot$ Achim G. Beule ${ }^{2,6} \cdot$ Jan-Christoffer Lüers ${ }^{3} \cdot$ Orlando Guntinas-Lichius $^{4} \cdot$ Leigh J. Sowerby $^{5}$. \\ Daniel Grafmans ${ }^{1}$
}

Received: 4 August 2020 / Accepted: 28 August 2020 / Published online: 8 September 2020

(c) Springer-Verlag GmbH Germany, part of Springer Nature 2020

\begin{abstract}
Purpose SARS-CoV-2 is detected on the mucosa of the upper airways to a high degree. In the course of the COVID-19 pandemic, otorhinolaryngologists (ORL) are assumed to be at high risk due to close contact with the mucosa of the upper airways. No data are yet available providing evidence that ORLs have an increased risk of infection.

Methods German ORLs were invited via e-mail through the German Society of ORL, Head and Neck Surgery and the German ENT Association to participate in a web-based survey about infection with SARS-CoV-2 and development of COVID19. Data of infections and concomitant parameters in German ORLs were collected and compared to the total number of infections in Germany.

Results Out of 6383 German ORLs, 970 (15\%) participated. 54 ORLs reported testing positive for SARS-CoV-2. Compared to the total population of Germany, ORLs have a relative risk of 3.67 (95\% CI 2.82; 4.79) of contracting SARS-CoV-2. Domestic quarantine was conducted in $96.3 \%$ of cases. Two individuals were admitted to hospital without intensive care. No casualties were reported. In 31 cases, the source of infection was not identifiable whereas 23 had a clear medical aetiology: infected patients: $n=5,9.26 \%$; medical staff: $n=13,14.1 \% .9 .26 \%(n=5)$ of the identified cases were related to contact to infected family members $(n=3)$, closer neighbourhood $(n=1)$ or general public $(n=1)$. There was no identified increased risk of infection due to performing surgery.

Conclusion German ORLs have an almost 3.7-fold risk of contracting SARS-CoV-2 compared to the population baseline level. Appropriate protection appears to be necessary for this occupational group.
\end{abstract}

Keywords Health care worker · SARS-CoV-2 · COVID-19 · ENT · Upper airway · ORL

Michael Herzog

M.Herzog@ctk.de

1 Department of Otorhinolaryngology, Head and Neck Surgery, Klinik für Hals-Nasen-Ohrenheilkunde, CarlThiem-Klinikum, Thiemstr. 111, 03048 Cottbus, Germany

2 Department of Otorhinolaryngology, University Hospital Münster, Munster, Germany

3 Department of Otorhinolaryngology, Medical Faculty, University of Cologne, Cologne, Germany

4 Department of Otorhinolaryngology, University Hospital Jena, Jena, Germany

5 Department of Otolaryngology, Head and Neck Surgery, Western University, London, ON, Canada

6 Department of Otorhinolaryngology, Head and Neck Surgery, University Medicine Greifswald, Greifswald, Germany

\section{Introduction}

The COVID-19 pandemic has had a profound impact on health care professionals all over the world. Anecdotal case reports at a relatively early stage of the COVID-19 pandemic suggested a higher risk for otorhinolaryngologists (ORLs) to contract SARS-CoV-2. Those early reports did not originate from peer-reviewed publications but from the public international press [1] or from private correspondences with ORLs in the regions first affected by COVID-19 [2]. Published data subsequently provided evidence of a high viral expression on the mucosa of the upper airway [3] combined with a high risk of viral transmission by aerosols $[4,5]$. The combination of those early individual statements and first scientific publications led to the assumption that ORLs would potentially be significantly exposed and at risk [6-8]. Several groups of ORLs subsequently provided recommendations 
based on limited evidence for otorhinolaryngological procedures [2] which were rapidly adopted worldwide. These published papers and web-based statements contain precise recommendations for the performance of certain surgical procedures (e.g., tracheostomies) [9-17]. Others provide general protection advice for ORLs [18-27] or similarly atrisk disciplines [28, 29]. Out of an abundance of caution, some otorhinolaryngological procedures like anterior rhinoscopy or the use of rigid or flexible endoscopes [30-33] were advised to be avoided unless absolutely necessary.

A recent publication provides data of infected or died ORLs from all over the world [34]. But at the moment, there are no data available about the risk of ORLs contracting SARS-CoV-2 or developing COVID-19 compared to a total population of a country. Moreover, there is little evidence if the recommendations mentioned above help to reduce the risk of infection for ORLs. In attempt to shed further light on this assumption, a national survey of all ORLs in Germany was performed to collect information about SARS-CoV-2 infection and development of COVID-19.

\section{Methods}

The web-based survey was launched, supported by the German Society of Oto-Rhino-Laryngology, Head and Neck Surgery (DGHNOKHC) and the German ENT Association (HNO Berufsverband, HNOBV). ORLs all over Germany were addressed via the mailing lists of each association and asked to participate. All recipients were asked to respond regardless of SARS-CoV-2 status. The web-based survey was performed by SurveyMonkey (San Mateo, CA, USA) and offered the choice to answer the questions for oneself as well as for seriously ill colleagues. The questionnaire consisted of 20 questions covering general information (age, gender, federal state and type of working site, type of performed medical procedures and surgeries) and specific tasks related to a potential infection by SARS-CoV-2 or COVID-19 (potential contact to infected individuals, date of own testing positive and re-testing negative, date and type of clinical symptoms, type of therapy, duration of disease, potential or verified source of infection). Additionally, the availability of personal protective equipment was assessed and respondents were asked about their perceived risk of getting infected during work. The participation was on a voluntary and anonymous basis. The period of the survey was continuously from 17 April 2020 (DGHNOKHC) and 22 April 2020 (HNOBV) respectively until 31 May 2020. One email reminder went out on 15 May 2020. This base line survey aimed to cover as many ORLs in Germany as possible independent from the infectious state. A followup survey was launched 1 June 2020 immediately after the base line survey and it is still active. Only those ORLs who get infected in the course of the pandemic are requested to participate. Data collection for the manuscript terminated 30 June 2020.

The survey intended to reach all ORLs in Germany. 3518 colleagues were mailed by the DGHNOKHC and 4179 by the HNOBV (in total, 7697 potential respondents). Due to the fact that some ORLs are members of both associations the total number of ORLs is over-estimated. Therefore, the number of ORLs given by the German Medical Association (bundesärztekammer.de) at 31 December 2019 in Germany $(n=6383)$ was chosen for the calculations conducted in this study. The epidemiological data for Germany on SARSCoV-2/COVID-19 were provided by the Robert-KochInstitute (www.rki.de).

Literature was searched in PubMed using the terms "COVID-19", "SARS-CoV-2" and "health care professional", "medical staff", "otorhinolaryngologist", "ear nose and throat", "ENT", "ORL" up to May 312020 with no language restriction.

\section{Results and findings}

\section{Demographic data of the base line survey}

A total of 970 individuals took part in the base line survey (male $n=577-59.5 \%$; female $n=393-40.5 \%$ ). Due to the anonymous set up of the survey it was not possible to assign the participants to a certain association (DGHNOKHC or HNOBV). Based on the provided number of ORLs in Germany ( $n=6383$, German Medical Association), the rate of participation was $15.2 \%$.

The age distribution and the federal states of the all participants of the base line as well as of all infected participants (base line and follow-up survey) are given in Tables 1, 2. The infected ORLs tended to be younger at the age group between 30 and 35 years. In the federal states of Bayern, Baden-Württemberg and Nordrhein-Westfalen most infections were reported.

620 persons $(63.92 \%)$ were working as private ORLs (among them-175 (18.04\%) as an attending physician in a hospital). 296 (39.52\%) persons were working in a hospital (66 heads of department, 121 senior physicians, 109 resident physicians). Among them, 106 (10.92\%) were performing special duties in intensive and critical care or performing nasopharyngeal swabs as part of the assessment team. Additional fields of activity were: "Medical administration" ( $n=30,3.09 \%)$, "not working at the moment (e.g., unemployed, parental leave)" ( $n=17,1.75 \%)$ and "not specified or other profession (e.g., retired)" $(n=15,1.55 \%)$. Due to the possibility of multiple choice answers, a simple summation of given answers does not apply. 
Table 1 Age distribution of the survey participants

\begin{tabular}{lccccc}
\hline \multirow{2}{*}{ Age (years) } & \multicolumn{2}{c}{ Total $(n=970)$} & & \multicolumn{2}{c}{ Infected $(n=54)$} \\
\cline { 2 - 3 } & $n$ & & & $n$ & \multicolumn{1}{c}{$\%$} \\
\hline$<30$ & 44 & 4.54 & 1 & 1.85 \\
$30-35$ & 109 & 11.24 & 11 & 20.37 \\
$36-40$ & 115 & 11.86 & 6 & 11.11 \\
$41-45$ & 154 & 15.88 & 5 & 9.26 \\
$46-50$ & 138 & 14.23 & 8 & 14.81 \\
$51-55$ & 148 & 15.26 & 10 & 18.52 \\
$56-60$ & 129 & 13.30 & 7 & 12.96 \\
$61-65$ & 83 & 8.56 & 3 & 5.56 \\
$66-70$ & 29 & 2.99 & 3 & 5.56 \\
$>70$ & 21 & 2.16 & 0 & 0 \\
\hline
\end{tabular}

Data are displayed for all participants (total—base line survey) as well as infected persons (infected-base line and follow-up survey) in total numbers $(n)$ and percentage (\%)

Table 2 Federal state distribution of the survey participants

\begin{tabular}{|c|c|c|c|c|}
\hline \multirow[t]{2}{*}{ Federal state } & \multicolumn{2}{|c|}{$\operatorname{Total}(n=970)$} & \multicolumn{2}{|c|}{$\begin{array}{l}\text { Infected } \\
(n=54)\end{array}$} \\
\hline & $n$ & $\%$ & $n$ & $\%$ \\
\hline Baden-Württemberg & 138 & 14.23 & 11 & 20.37 \\
\hline Bayern & 144 & 14.85 & 9 & 16.67 \\
\hline Berlin & 58 & 5.98 & 4 & 7.41 \\
\hline Brandenburg & 46 & 4.74 & 2 & 3.7 \\
\hline Bremen & 15 & 1.55 & 1 & 1.85 \\
\hline Hamburg & 48 & 4.95 & 5 & 9.26 \\
\hline Hessen & 59 & 6.08 & 1 & 1.85 \\
\hline Mecklenburg-Vorpommern & 20 & 2.06 & 0 & 0 \\
\hline Niedersachsen & 71 & 7.32 & 3 & 5.56 \\
\hline Nordrhein-Westfalen & 185 & 19.07 & 8 & 14.81 \\
\hline Rheinland-Pfalz & 29 & 2.99 & 2 & 3.7 \\
\hline Saarland & 8 & 0.82 & 0 & 0 \\
\hline Sachsen & 54 & 5.57 & 0 & 0 \\
\hline Sachsen-Anhalt & 37 & 3.81 & 3 & 5.56 \\
\hline Schleswig-Holstein & 25 & 2.58 & 5 & 9.26 \\
\hline Thüringen & 33 & 3.40 & 0 & 0 \\
\hline
\end{tabular}

Data are displayed for all participants (total—base line and follow-up survey) as well as infected persons (infected-base line and follow-up survey) in total numbers $(n)$ and percentage (\%)

$63.10 \%(n=578)$ of all responders $(n=916 ; n=54$ were non responders to that question) were not active professionally on a regular base. Among the infected ORLs $(n=35)$ $59.26 \%$ did not work regularly. This fact is interesting because the path of infection might not be explained with a professional exposition to potential infected patients or other health care workers. If ORL-procedures were performed, a clinical examination was conducted in most of the cases. Among the infected ORLs there was an increased use of endoscopes and surgery was performed more often in percent.

Regularly performed medical procedures (conservative and surgical) are displayed in Table 3.

There was known contact with SARS-CoV-2 positive individuals in 349 participants ( $38.5 \%$ of $n=907$ ) —patients $n=238$ (68.2\%), medical staff $n=70$ (20.1\%), family $n=8$ (2.2\%), extended private circle $n=32(9.2 \%)$, general public $n=1(0.3 \%)$. The other participants $(n=578,61.5 \%$ of $n=907)$ had no known contact and $63(6.8 \%)$ did not respond to this question.

There were 916 participants who replied regarding their perception of protection provided at work. The infected ORLs felt less protected during medical work compered to non-infected colleagues (Table 4).

The available personal protective equipment is displayed in Table 5.

\section{SARS-CoV-2 positive participants}

In the base line survey, 35 participants had tested positive for SARS-CoV-2. Another 19 ORLs reported to be tested positive in the follow-up survey. All infected ORLs $(n=54)$ provided the date of positive testing between 13 March 2020 and 24 June 2020 (Fig. 1). There were 34 male and 20 female positive cases. The distribution by 5 -year-intervals and the distribution among the federal states of Germany are given in Tables 1,2, respectively. The first report was dated 13 March 2020 and was located in Rheinland-Pfalz. The cumulative course is given in Fig. 1. Among all infected participants ( $n=54), 22$ were working in a hospital (one head of the department, seven senior physicians, 14 resident physicians). 31 participants were working in private practice (ten attending physicians). One ORL indicated other professional activities as the contact of SARS-CoV-2 positive persons.

\section{Course of disease of the SARS-CoV-2 positive participants}

In 36 participants, clinical symptoms were present before being tested positive for SARS-CoV-2. Ten individuals had symptoms and a positive testing at the same day. In eight participants, symptoms occurred after the testing (Fig. 2). The most common symptom abnormal fatigue $68.52 \%(n=37)$. Other multiple symptoms were: Fever (50\%, $n=27)$, musculo-skeletal pain $(48.15 \%, n=26)$, cough $(38.89 \%, n=21)$, hyposmia $(38.89 \%, n=21)$, sore throat $(25.93 \%, n=14)$, coryza $(22.22 \%, n=12)$, dyspnea $(12.96 \%, n=7)$, headache $(5.56 \%, n=3)$. Singular reported complaints were: shiver, pharyngeal mucous obstruction, neuralgic facial pain, angioedema, thoracal pressure, nausea, 
Table 3 Examination, testing and surgical activities of respondents

\begin{tabular}{|c|c|c|c|c|}
\hline \multirow[t]{2}{*}{ Medical activities } & \multicolumn{2}{|c|}{ Total $(n=916)$} & \multicolumn{2}{|c|}{ Infected $(n=54)$} \\
\hline & $n$ & $\%$ & $n$ & $\%$ \\
\hline No examination/surgery & 578 & 63.10 & 32 & 59.26 \\
\hline Conservative activities & 193 & 21.07 & 13 & 24.07 \\
\hline Examination of the nose & 216 & 23.58 & 15 & 27.78 \\
\hline Examination of the oral cavity & 230 & 25.11 & 16 & 29.63 \\
\hline Examination of the pharynx and larynx & 171 & 18.67 & 16 & 29.63 \\
\hline Examination of the ears & 164 & 17.0 & 12 & 22.22 \\
\hline Use of endoscopes & 145 & 15.83 & 14 & 25.93 \\
\hline Sonography & 85 & 9.28 & 6 & 11.11 \\
\hline Audiometric and vestibular testing & 52 & 5.68 & 4 & 7.41 \\
\hline Rhinologic testing & 25 & 2.73 & 2 & 3.37 \\
\hline Others & 34 & 3.71 & 0 & 0 \\
\hline Surgery & 44 & 4.80 & 8 & 14.81 \\
\hline Mucosa associated surgery & 30 & 3.8 & 1 & 1.85 \\
\hline Nose/paranasal sinus & 21 & 2.29 & 2 & 3.37 \\
\hline Tonsillectomy & 7 & 0.76 & 0 & 0 \\
\hline Panendoscopy & 11 & 1.20 & 0 & 0 \\
\hline Tumor surgery & 10 & 1.09 & 1 & 1.85 \\
\hline Middle ear surgery & 5 & 0.55 & 0 & 0 \\
\hline Surgical tracheostomy & 45 & 4.91 & 2 & 3.37 \\
\hline Dilatation tracheostomy & 4 & 0.44 & 0 & 0 \\
\hline Other surgery & 6 & 0.66 & 0 & 0 \\
\hline Surgery without mucosa association & 7 & 0.76 & 1 & 1.85 \\
\hline Minor surgery (e.g., lymph node exstirpation) & 13 & 1.42 & 1 & 1.85 \\
\hline Major surgery (e.g., parotidectomy, neck dissection) & 6 & 0.66 & 0 & 0 \\
\hline Other surgery & 10 & 1.09 & 0 & 0 \\
\hline
\end{tabular}

The total number of surgical procedures in the infected group $(n=8)$ is low and therefore these data should be interpreted carefully. The high number of tracheostomies was to be expected according to potential scenarios for COVID-19. However, a total number of $n=2$ tracheostomies in the infected group does not support an increased risk of infection due to performing tracheostomies. Apart from that, it can be assumed that tracheostomies were conducted under sufficient protection as recommended by many statements of ORL-societies
Table 4 Perception of professional protection

\begin{tabular}{lrrrrr}
\hline \multirow{2}{*}{$\begin{array}{l}\text { Perception of pro- } \\
\text { tection }\end{array}$} & \multicolumn{2}{c}{ Total $(n=916)$} & & \multicolumn{2}{c}{ Infected $(n=54)$} \\
\cline { 2 - 3 } \cline { 6 - 6 } & $n$ & & & $n$ & $\%$ \\
\hline At any time & 87 & 9.50 & & 7.41 \\
Mostly & 416 & 45.41 & & 14 & 25.93 \\
Sometimes & 108 & 11.79 & 6 & 11.11 \\
Insufficient & 245 & 26.75 & & 20 & 37.04 \\
Not at all & 60 & 6.55 & & 10 & 18.52 \\
\hline
\end{tabular}

916 participants answered to the question "Do/Did you feel protected against an infection with SARS-CoV-2 during your professional activities?" Comparing the answers of all participants with those of the infected ORLs a reduced perception of protection gets obvious. $60 \%$ of the infected ORLs declared a reduced protection or no protection at all nocturnal sweating, cardiac arrhythmia and gastro-intestinal complaints. $11.11 \%(n=6)$ did not report any complaints.

In $96.3 \%$ of the cases $(n=52)$, domestic quarantine without any specific therapy was the only treatment required. Two ORLs needed to be admitted to hospital on a regular ward (3.7\%): none of the infected surgeons needed respirator therapy or intensive care treatment). COVID-19-related deaths were not reported by third parties. The duration of the disease was reported to range below 12 days in 26 ORLs (48.15\%), 12-15 days $(n=9, \cdot 16.67 \%), 16-20$ days $(n=8$, $14.81 \%), 21-25$ days $(n=6,11.11 \%)$ and more than 25 days $(n=2,3.7 \%)$. Three participants $(5.56 \%)$ reported that the infection is still not over yet.

At termination of the base line $(n=34)$ survey on 31 May 2020, 24 infected participants had cleared the virus and in eleven cases re-testing had not yet been performed. 27 infected colleagues are already working again-among them seven persons without a repeat negative testing. Six 
Table 5 Available Personal Protective Equipment

\begin{tabular}{|c|c|c|c|c|}
\hline \multirow[t]{2}{*}{ Personal protective equipment } & \multicolumn{2}{|c|}{$\begin{array}{l}\text { Total } \\
(n=916)\end{array}$} & \multicolumn{2}{|c|}{$\begin{array}{l}\text { Infected } \\
(n=54)\end{array}$} \\
\hline & $n$ & $\%$ & $n$ & $\%$ \\
\hline Surgical masks (FFP1) & 551 & 60.15 & 37 & 68.52 \\
\hline Protective masks (FFP2) & 549 & 59.93 & 26 & 48.15 \\
\hline N95 masks (FFP3) & 202 & 22.05 & 10 & 18.52 \\
\hline Protective glasses & 572 & 62.45 & 30 & 55.56 \\
\hline $\begin{array}{l}\text { Protective helmet without air filtering } \\
\text { system }\end{array}$ & 79 & 8.62 & 4 & 7.41 \\
\hline Helmet with active filtering system (PAPR) & 20 & 2.18 & 1 & 1.85 \\
\hline Gloves & 833 & 90.94 & 46 & 85.19 \\
\hline Protective coats & 481 & 52.51 & 22 & 40.74 \\
\hline Others & 126 & 13.76 & 3 & 5.56 \\
\hline
\end{tabular}

916 participants answered to the question "What kind of private protection equipment was/is sufficiently available? Multiple choice possible". Both groups did not differ significantly. Notably, surgical face masks (FFP1) were available in just $60 \%$ of the cases. Conversely, it might be assumed that $40 \%$ did not sufficient face masks

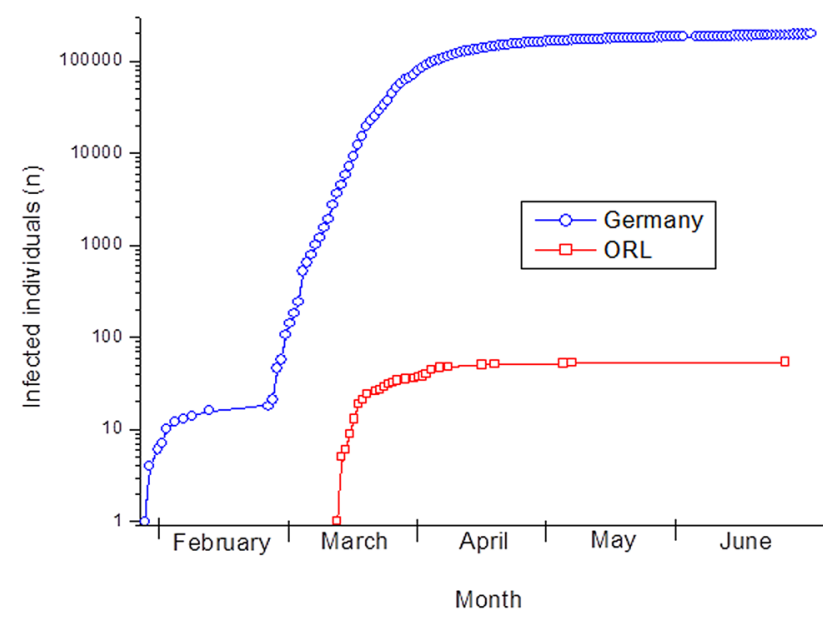

Fig. 1 Cumulative increase of infections by SARS-CoV-2. Increase of confirmed infections by SARS-CoV-2 among the German population (blue) and among ORLs (red). The logarithmic curve reveals an increase since 28 January 2020 in Germany which is caused by a local event of 16 infected persons in Bavaria. Since 26 February 2020, an exponential increase is detectable in Germany. The first infection in ORLs is reported for 13 March 2020. The curve of infected ORLs is delayed for 2 weeks, reveals a similar exponential growth and flattens parallel to the curve of total infections. The last infection in ORLs is documented for 24 June 2020

colleagues were still diseased and two participants did not give any data. The participants of the follow-up survey reported a negative re-testing in 15 cases whereas four had not been tested yet. All infected ORLs of the follow-up survey $(n=19)$ are working again.

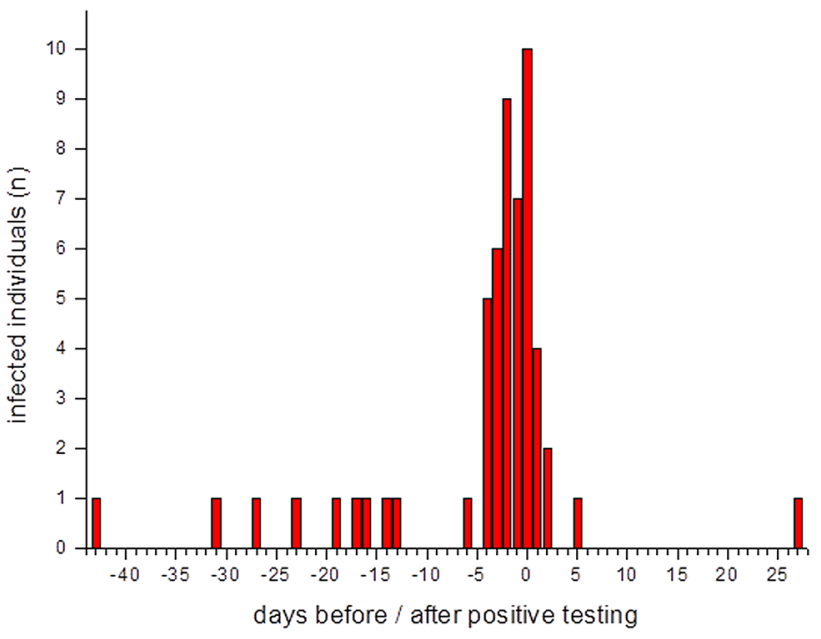

Fig. 2 Occurrence of clinical symptoms with respect to the date of the positive testing for SARS-Cov-2. The day of testing is indicated by " 0 " on the $X$-axis. The time before testing is indicated by "-" given in days. Positive numbers indicate the occurrence of symptoms after testing at day " 0 "

\section{Working conditions of the SARS-CoV-2 positive participants}

Among the positive reported ORLs ( $n=54$, base line and follow-up survey), 34 did not have any known contact with known infected persons. A clinical otorhinolaryngological examination (especially of the upper airway) was performed by 20 participants in SARS-CoV-2 positive patients. 14 ORLs used endoscopes for these procedures. Eight participants were doing surgery $(2 \times$ tracheostomy, $2 \times$ nose and sinus surgery, $2 \times$ minor neck surgery, $1 \times$ tumor surgery, $1 \times$ surgery on mucosa). Nine infected colleagues reported a relationship between the medical procedures and their own infection. 15 participants did not assume an association to their medical activities. 30 participants could not give specific information.

In $57.41 \%(n=31)$ of the cases the path of infection is not clear. More than one third is assumed to be related to the professional circumstances (contact to infected patients: $n=5,9.26 \%$; contact to infected medical staff: $n=13$, $14.1 \%) .9 .26 \%(n=5)$ of the identified cases were related to contact to infected family members $(n=3)$, closer neighbourhood $(n=1)$ or general public $(n=1)$.

\section{Correlation of SARS-CoV-2 positive participants with the total population in Germany}

The base line survey was active from 17 April 2020 until 31 May 2020. The follow-up survey provides data from 1 June until 30 June 2020. The relationship between infected ENT colleagues and the total population of Germany is performed 
with the cumulated number of infections at the last date of a reported infection (24 June 2020).

By 24 June 2020 (last positive report of the survey), 54 ORLs reported positive tests. At that date, 191,449 persons were registered as infected in Germany (daily report Robert-Koch-Institute for 24 June 2020; www.rki.de). Infected ORLs represented $0.028 \%$ of the total infections in Germany.

These 54 infected ORLs represent $0.85 \%$ of all ORLs in Germany ( $n=6383)$. 6329 ORLs were considered as not infected. At the same date (24 June 2020), 191449 infected persons of the total population of 83,149,300 in Germany (Federal Statistical Office, 30 September 2019) represent $0.23 \%$ infected persons of the total population of Germany. $82,957,851$ persons of the total population were considered as not infected. With respect to these data, the percentage of infected ORLs is 3.7 times as high as for the total German population.

The relative risk of a positive test for SARS-CoV-2 for ORLs in Germany is 3.67 (95\% CI 2.82; 4.79).

\section{Discussion}

Health care professionals are assumed to have a higher risk of contracting SARS-CoV-2 or to suffer from COVID-19. According to Chinese data, $3.8 \%$ of COVID-19 patients are medical staff [35]. Persons who have professional contact with the mucosa of the upper airways are said to be especially at risk. This hypothesis is present since the beginning of the pandemic and is supported by available evidence that the viral load is extraordinary high in the mucosa of the upper airway [3]. Thus, ORLs seem to be at higher risk [36]. Nevertheless, there is, as of yet, no valid data supporting this hypothesis.

The aim of the survey was to obtain data about the total number and percentage of infected ORLs in Germany as well as the geographical accumulation, the time course and work-related circumstances. Moreover, the survey intended to collect data about potential risk factors and infection paths. In an international context, very little similar data are available. Moreover, no data are available about the time course, clinical symptoms and course of infection for COVID-19 in ORLs.

Some methodical restrictions of the study methodology should be discussed. In Germany, a reasonable suspect and proven infection with SARS-CoV-2 are reportable to public health. The report to the local public health department does not include the professions of the reported persons and it is not possible to identify medical staff or ORLs. As such, the detection of the infection rate among ORLs is only possible by addressing physicians individually who are listed in one of the two national associations (DGHNOKHC; BVHNO). A survey, by nature is also voluntary. A rate of return of $15.2 \%$ was lower than expected for such an unprecedented event but is comparatively high for a web-based survey. Lastly, as the survey was anonymous it was not possible to follow-up for additional information, and it would have theoretically been possible for dishonest answers to be recorded.

In the course of dishonest answers, the record of COVID19-related casualties comes to the fore. Unfortunately, there are no data available by the RKI or any other official register in Germany correlating casualties with profession or even medical subspecialisations like ORL. The information about casualties in the presented study is based on the survey. At the end of the questionnaire the participants were asked if they have knowledge of any COVID-19-related casualties of ORL-colleagues. In general, the relationship among ORLs is very close and casualties would not occur unnoticed. If a participant had knowledge of colleagues who died in the course of COVID-19, she/he was asked to re-fill the survey as a "third party representative" reporting a COVID-19-associated death of an ORL colleague. An appeal to everyone's self-responsibility was addressed not to give dishonest answers and to confer with other colleagues of the environment of the deceased ORL to avoid double responses. Of course, this issue underlies a limitation which cannot be denied and should be kept in mind when interpreting the data of the survey.

The occurrence of the infection correlates with a time shift of approximately 2 weeks to all infections in Germany. The infection curve for ORLs reveals a similar exponential growth at the beginning of the pandemic and a flattening of the curve over the time - similar to the curve of all infections in Germany. It can be assumed that the general sanctions to limit the disease also limited the rate of infections in ORLs.

Of course, it would have been of interest to evaluate the risk of infections for ORLs not only for Germany in total but also depending on the federal state as well as on the course of infection. If considering such an evaluation one needs to have enough infected ORLs over all (or at least some) federal states at different times. In this survey, there were "only" 8, 9 and 11 infected ORLs in Nordrhein-Westfalen, Bayern and Baden-Württemberg - the most affected federal states in Germany,respectively. All other federal states revealed even lower numbers of infected ORLs. On the base of such a reduced number, analyses focused on federal states seem to be questionable at the moment.

Nevertheless, the survey remains active as a follow-up and it is intended to have a closer look at several aspects as soon as the number of infected ORLs is sufficient for statistical analyses.

Several working groups and medical societies have published position papers dealing with otorhinolaryngological procedures. These publications cover activities of daily professional routine as well as surgical procedures which were supposed to occur especially in long-time ventilated 
patients. Tracheostomies are among the mostly discussed surgical procedures because it is/was assumed that these surgical procedures might be necessary in COVID-19 patients. According to the present data, elective surgeries were mostly reduced in Germany as mandated by the German ministry of health. Surgical tracheostomies were conducted at a surprisingly high number $(n=45)$. The conclusion that an infection with SARS-CoV-2 is frequently correlated to performing tracheostomies is not likely, as only two infected ORLs performed a tracheostomy. Most probably, adequate protective clothing when performing aerosol-forming surgery has contributed to that low number.

The data provide evidence that ORLs working in a private practice get infected more often than colleagues in hospitals (31 vs. 22). Despite a reduction of clinical examinations performed by ORLs in private practice $(63.1 \%$ did not perform an examination anymore) approximately $37 \%$ of the ORLs continued to do clinical examinations. Data about COVID19 in hospital health care workers in Wuhan illustrate that the probability of an infection when having contact to the mucosa and performing surgery are listed just behind working in an emergency department and intensive care unit [37, 38]. In these publications, infections are correlated in approximately $50 \%$ with contacts to infected patients and one quarter with infected medical staff. Contrary to these data, the German infected ORLs revealed more infections due to contact to infected medical staff although in all ORLs a knowingly contact to infected persons was more often in patients than in infected medical staff. On basis of this data, it could be assumed that precautions might have been neglected when dealing with other health care professionals.

Interestingly, the aetiology of infection was traceable in only one third of the infected ORLs in Germany. From the trackable cases, roughly one third were correlated to infected patients and two thirds to infected health care personal. Over $57 \%$ of the infection paths were not trackable at all. It can be assumed that due to the high rate of new infections in March and April 2020 (Fig. 1) clear contract tracing was not possible.

According to a meta-analysis the prevalence of contracting SARS-CoV-2 for German ORLs (own data: 0.85\%) compared to health care workers in China $(5.1 \%)$ or the Netherlands (6.4\%) [39]. Certainly, those data are not comparable to the German ones due to differences in the time course and intensity of the pandemic as well as discrepancies in the samples and methods of data acquisition. Nevertheless, there seems to be evidence that health care professionals are facing a higher risk of getting infected not only in hospitals, but also in private doctor's offices.

With regard to the age distribution of the infected ORLs, the validity is limited due to a total number of 54 . An accumulation of infections at the age group between 46 and 55 years was seen but most participants belong to that age group and it represents the age distribution of working ORLs in Germany. However, there tends to be a slight shift towards a younger age for infected ORLs in the survey (Table 1). In the age group between 30 and 35 years, an accumulation (20.37\%) is detectable although the total participation at that age is lower (11.24\%). It can be discussed that ORLs working in hospitals tend to be younger and got infected performing routine ORL procedures. It may also be that older ORLs may have taken increased precautions given the known association of increasing morbidity with increasing age. Based on these data, it cannot be concluded that younger physicians got infected when being appointed to special procedures because only one out of 35 infected ORLs actually was in temporarily employment in an intensive care or swab taking unit.

The extent to which new infections were reduced by the application of personal protective equipment in the ORLs of the present survey can only be estimated. There is evidence that the infection rate can be reduced by the use of face masks and eye protection [40]. Normal face masks (FFP1) were available for approximately two thirds of the respondents. Conversely, one third of the respondents were insufficiently protected when doing their routine work. In N95 face masks (FFP3) the shortage is reported to be even higher. These responses correlate chronologically with the supply shortage at the beginning of the pandemic. It could be a task for a follow-up survey to evaluate if the supply has improved meanwhile. Despite all shortages, many respondents felt adequately protected. However, infected ORLs reported to an increasing degree that they felt insufficiently or not at all protected. It cannot easily be determined if the reported shortage of personal protective equipment could serve as the reason for their own infections of the ORLs or if any unconscious retrospective blaming takes place. A potential causality should be kept in mind when interpreting these data.

The results of the present survey provide substantial data about a potential increased risk of infection by SARS-CoV-2 for ORLs. On the basis of the provided evidence, ORLs might be supported adequately during future pandemic events. Moreover, ORLs should be involved in taskforces if symptoms of a specific pandemic disease are found in the otorhinolaryngological field [41] and the data might also serve as comparative figures for other medical specialities.

In summary, the present data reveal a relative risk of 3.67 for ORLs compared to the total population of Germany to get infected by SARS-CoV-2. Thus, the data support the hypothesis that ORLs have a higher risk to get infected by SARS-CoV-2. It still remains ambiguous how high the risk of infection is for other health care professionals. Certainly, sufficient personal protection equipment needs to be available for otorhinolaryngologists especially if a second or third wave of infection by SARS-CoV-2 must be expected and 
COVID-19 will turn into a long lasting medical challenge all over the world.

Acknowledgements The authors would like to thank the German Society of Oto-Rhino-Laryngology, Head and Neck Surgery, the German ENT Association and the Young Otolaryngologists-International Federation of Otolaryngologic Societies (YO-IFOS) for their support. Jasmin Renchen (DGHNOKHC) provided support with SurveyMonkey.

Author contributors $\mathrm{MH}, \mathrm{AGB}, \mathrm{JCL}, \mathrm{OGL}$ and DG contributed to the study design and literature search. Data collection and figure preparation were performed by MH. MH, AGB, JCL, OGL, LJS and DG contributed to data analysis, data interpretation as well as writing, drafting, revising, and approval.

Funding No funding.

\section{Compliance with ethical standards}

Conflict of interest The authors declare that they have no conflict of interest.

Ethical approval The study was approved by the German Society of Oto-Rhino-Laryngology, Head and Neck Surgery and the German ENT Association.

\section{References}

1. China Newsweek View. https://inews.qq.com/a/20200125A0 7TT200?uid=\&devid=BDFE70CD-5BF1-4702-91B7-329F2 0A6E839\&qimei=bdfe 70cd-5bf1-4702-91b7-329f20a6e839. Accessed 25 Jan 2020

2. Patel ZM, Hwang PH, Nayak JV et al. COVID-19SinusSurgeryInfo. Stanford University School of Medicine, Departments of Otolaryngology-H\&N Surgery and Neurosurgery. https://med.uth. edu/orl/wp-content/uploads/sites/68/2020/03/Update-on-Preca utions-Regarding-Endoscopic-Procedures-and-COVID-19-202003-22.pdf. Accessed 22 Mar 2020

3. Zou L, Ruan F, Huang M et al (2020) SARS-CoV-2 viral load in upper respiratory specimens of infected patients. N Engl J Med 382(12):1177-1179. https://doi.org/10.1056/NEJMc2001737

4. van Doremalen N, Bushmaker T, Morris DH et al (2020) Aerosol and surface stability of SARS-CoV-2 as compared with SARS-CoV-1. N Engl J Med 382(16):1564-1567. https://doi. org/10.1056/NEJMc2004973

5. Judson SD, van Doremalen N, Munster VJ (2020) Stability and viability of SARS-CoV-2. Reply N Engl J Med. https://doi. org/10.1056/NEJMc2007942

6. Krajewska J, Krajewski W, Zub K et al (2020) COVID-19 in otolaryngologist practice: a review of current knowledge. Eur Arch Otorhinolaryngol. https://doi.org/10.1007/s00405-020-05968-y

7. Philpott C, Burrows S. Aerosol-generating procedures in ENT. https://www.entuk.org/aerosol-generating-procedures-ent. Accessed 23 Mar 2020

8. Lüers J-C, Klußmann JP, Guntinas-Lichius O (2020) Die Covid-19-pandemie und das HNO-Fachgebiet: Worauf kommt es aktuell an? (The Covid-19 pandemic and otolaryngology: what it comes down to?). Laryngorhinootologie. https://doi. org/10.1055/a-1095-2344

9. Lüers J-C, Klußmann JP, Guntinas-Lichius O (2020) Die Covid19-pandemie und das HNO-Fachgebiet: Worauf kommt es aktuell an? (The Covid-19 pandemic and otolaryngology: what it comes down to?). Laryngorhinootologie 99(5):287-291. https://doi. org/10.1055/a-1095-2344

10. Crossley J, Clark C, Brody F et al (2020) Surgical considerations for an awake tracheotomy during the COVID-19 pandemic. J Laparoendosc Adv Surg Tech A. https://doi.org/10.1089/ lap. 2020.0239

11. David AP, Russell MD, El-Sayed IH et al (2020) Tracheostomy guidelines developed at a large academic medical center during the COVID-19 pandemic. Head Neck. https://doi.org/10.1002/ hed.26191

12. Goldman RA, Swendseid B, Chan JYK et al (2020) Tracheostomy management during the COVID-19 pandemic. Otolaryngol Head Neck Surg. https://doi.org/10.1177/0194599820923632

13. Kligerman MP, Vukkadala N, Tsang RKY et al (2020) Managing the head and neck cancer patient with tracheostomy or laryngectomy during the COVID-19 pandemic. Head Neck. https://doi. org/10.1002/hed.26171

14. Lindemann J, Böhm F, Hoffmann T et al (2020) Chirurgische Aspekte zur Tracheostomie bei Covid-19 positiven Patienten. Laryngorhinootologie 99(05):282-284. https://doi. org/10.1055/a-1151-7932

15. Portugal LG, Adams DR, Baroody FM et al (2020) A surgical safety checklist for performing tracheotomy in patients with coronavirus disease 19. Otolaryngol Head Neck Surg. https://doi. org/10.1177/0194599820922981

16. Saadi RA, Bann DV, Patel VA et al (2020) A commentary on safety precautions for otologic surgery during the COVID19 pandemic. Otolaryngol Head Neck Surg. https://doi. org/10.1177/0194599820919741

17. Sommer DD, Engels PT, Usaf CEKW et al (2020) Recommendations from the CSO-HNS taskforce on performance of tracheotomy during the COVID-19 pandemic. J Otolaryngol Head Neck Surg 49(1):23. https://doi.org/10.1186/s40463-020-00414-9

18. AAO-HNS Position Statement: Otolaryngologists and the COVID-19 pandemicAAO-HNS position statement: otolaryngologists and the COVID-19 pandemic. https://www.entnet.org/ content/aao-hns-position-statement-otolaryngologists-and-covid -19-pandemic. Accessed 23 Mar 2020

19. Fakhry N, Schultz $P$, Morinière $S$ et al (2020) French consensus on management of head and neck cancer surgery during COVID-19 pandemic. Eur Ann Otorhinolaryngol Head Neck Dis. https://doi. org/10.1016/j.anorl.2020.04.008

20. Givi B, Schiff BA, Chinn SB et al (2020) Safety recommendations for evaluation and surgery of the head and neck during the COVID-19 pandemic. JAMA Otolaryngol Head Neck Surg. https ://doi.org/10.1001/jamaoto.2020.0780

21. Hennessy M, Bann DV, Patel VA et al (2020) Commentary on the management of total laryngectomy patients during the COVID-19 pandemic. Head Neck. https://doi.org/10.1002/hed.26183

22. Hsieh T-Y, Dedhia RD, Chiao W et al (2020) A guide to facial trauma triage and precautions in the COVID-19 pandemic. Facial Plast Surg Aesthet Med. https://doi.org/10.1089/fpsam.2020.0185

23. Leboulanger N, Sagardoy T, Akkari M et al (2020) COVID-19 and ENT Pediatric otolaryngology during the COVID-19 pandemic. Guidelines of the French association of pediatric otorhinolaryngology (AFOP) and French society of otorhinolaryngology (SFORL). Eur Ann Otorhinolaryngol Head Neck Dis. https://doi. org/10.1016/j.anorl.2020.04.010

24. Lu D, Wang H, Yu R et al (2020) Integrated infection control strategy to minimize nosocomial infection of coronavirus disease 2019 among ENT healthcare workers. J Hosp Infect 104(4):454-455. https://doi.org/10.1016/j.jhin.2020.02.018

25. Parker NP, Schiff BA, Fritz MA et al. Tracheotomy recommendations during the COVID-19 pandemic. American Academy of Otorhinolaryngology—Head and Neck Surgery. https://www. 
entnet.org/content/tracheotomy-recommendations-during-covid -19-pandemic. Accessed 27 Mar 2020

26. Xu K, Lai XQ, Liu Z (2020) Suggestions for prevention of 2019 novel coronavirus infection in medical staff of otolaryngology head and neck surgery. Zhonghua Er Bi Yan Hou Tou Jing Wai Ke Za Zhi 55(4):313-315. https://doi.org/10.3760/cma.j.cn115 330-20200201-00240

27. Yang XL, Ren J, Xu Z et al (2020) Prevention and control strategies and methods of novel coronavirus epidemic infection in department of otolaryngology head and neck surgery in hospital. Zhonghua Er Bi Yan Hou Tou Jing Wai Ke Za Zhi 55(4):316-321. https://doi.org/10.3760/cma.j.cn115330-20200205-00237

28. Patel ZM, Fernandez-Miranda J, Hwang PH et al (2020) Letter: PRECAUTIONS for endoscopic transnasal skull base surgery during the COVID-19 pandemic. Neurosurgery. https://doi. org/10.1093/neuros/nyaa125

29. Iorio-Morin C, Hodaie M, Sarica C et al (2020) Letter: the risk of COVID-19 infection during neurosurgical procedures: a review of severe acute respiratory distress syndrome coronavirus 2 (SARS-CoV-2) modes of transmission and proposed neurosurgery-specific measures for mitigation. Neurosurgery. https://doi. org/10.1093/neuros/nyaa157

30. Chan JYK, Wong EWY, Lam W (2020) Practical aspects of otolaryngologic clinical services during the 2019 Novel coronavirus epidemic: an experience in Hong Kong. JAMA Otolaryngol Head Neck Surg. https://doi.org/10.1001/jamaoto.2020.0488

31. Chan JYK, Tsang RKY, Yeung KW et al (2020) There is no routine head and neck exam during the COVID-19 pandemic. Head Neck. https://doi.org/10.1002/hed.26168

32. Kowalski LP, Sanabria A, Ridge JA et al (2020) COVID-19 pandemic: effects and evidence-based recommendations for otolaryngology and head and neck surgery practice. Head Neck. https ://doi.org/10.1002/hed.26164

33. Rameau A, Young VN, Amin MR et al (2020) Flexible laryngoscopy and COVID-19. Otolaryngol Head Neck Surg. https://doi. org/10.1177/0194599820921395

34. Sowerby LJ, Stephenson K, Dickie A et al (2020) International registry of otolaryngologist-head and neck surgeons with COVID-19. Int Forum Allergy Rhinol. https://doi.org/10.1002/ alr.22677
35. Wu Z, McGoogan JM (2020) Characteristics of and important lessons from the coronavirus disease 2019 (COVID-19) outbreak in China: summary of a report of 72314 cases from the Chinese center for disease control and prevention. JAMA. https://doi. org/10.1001/jama.2020.2648

36. Cho RHW, Yeung ZWC, Ho OYM et al (2020) Pearls of experience for safe and efficient hospital practices in otorhinolaryngology-head and neck surgery in Hong Kong during the 2019 novel coronavirus disease (COVID-19) pandemic. J Otolaryngol Head Neck Surg 49(1):30. https://doi.org/10.1186/s40463-020-00427-4

37. Jin Y-H, Huang Q, Wang Y-Y et al (2020) Perceived infection transmission routes, infection control practices, psychosocial changes, and management of COVID-19 infected healthcare workers in a tertiary acute care hospital in Wuhan: a cross-sectional survey. Mil Med Res 7(1):24. https://doi.org/10.1186/s40779-02000254-8

38. Lai X, Wang M, Qin C et al (2020) Coronavirus disease 2019 (COVID-2019) infection among health care workers and implications for prevention measures in a tertiary hospital in Wuhan. China JAMA Netw Open 3(5):e209666. https://doi.org/10.1001/ jamanetworkopen.2020.9666

39. Chou R, Dana T, Buckley DI et al (2020) Epidemiology of and risk factors for coronavirus infection in health care workers. Ann Intern Med. https://doi.org/10.7326/M20-1632

40. Chu DK, Akl EA, Duda S et al (2020) Physical distancing, face masks, and eye protection to prevent person-to-person transmission of SARS-CoV-2 and COVID-19: a systematic review and meta-analysis. Lancet. https://doi.org/10.1016/S0140 $-6736(20) 31142-9$

41. Lechien JR, Chiesa-Estomba CM, Place S et al (2020) Clinical and epidemiological characteristics of 1420 European patients with mild-to-moderate coronavirus disease 2019. J Intern Med. https://doi.org/10.1111/joim.13089

Publisher's Note Springer Nature remains neutral with regard to jurisdictional claims in published maps and institutional affiliations. 